\title{
Shear wave splitting as a proxy for stress forecast of the case of the 2006 Manyas-Kus Golu $\left(M_{b}=5.3\right)$ earthquake
}

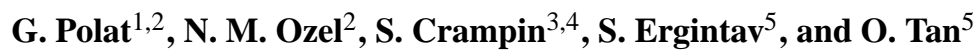 \\ ${ }^{1}$ Dublin Institute for Advanced Studies, Geophysics Section, 5 Merrion Square, Dublin 2, Ireland \\ ${ }^{2}$ Department of Geophysics, Kandilli Observatory and Earthquake Research Institute, Boğaziçi University, Istanbul, Turkey \\ ${ }^{3}$ British Geological Survey, Edinburgh EH9 3LA, Scotland, UK \\ ${ }^{4}$ School of Geosciences, University of Edinburgh, Edinburgh EH9 3FW, Scotland, UK \\ ${ }^{5}$ TUBITAK Marmara Research Center, Earth and Marine Sciences Institute (EMSI), Gebze, Turkey
}

Correspondence to: G. Polat (gultenpolat2005@gmail.com)

Received: 19 July 2011 - Revised: 10 November 2011 - Accepted: 25 January 2012 - Published: 17 April 2012

\begin{abstract}
The $2006 M_{\mathrm{b}}=5.3$ Manyas-Kus Golu (Manyas) earthquake has been retrospectively "stress-forecasted" using variations in time-delays of seismic shear wave splitting to evaluate the time and magnitude at which stress-modified microcracking reaches fracture criticality within the stressed volume where strain is released. We processed micro earthquakes recorded by 29 TURDEP (Multi-Disciplinary Earthquake Research in High Risk Regions of Turkey) and 33 KOERI (Kandilli Observatory and Earthquake Research Institute) stations in the Marmara region by using the aspectratio cross-correlation and systematic analysis of crustal anisotropy methods. The aim of the analysis is to determine changes in delay-times, hence changes in stress, before and after the 2006 Manyas earthquake. We observed that clear decreases in delay times before the impending event, especially at the station GEMT are consistent with the anisotropic poro-elasticity (APE) model of fluid-rock deformation, but we could not observe similar changes at other stations surrounding the main event. The logarithms of the duration of the stress-accumulation are proportional (self-similar) to the magnitude of the impending event. Although time and magnitude of th 2005 Manyas earthquake could have been stress-forecasted, as has been recognized elsewhere, shearwave splitting does not appear to provide direct information about the location of impending earthquakes.
\end{abstract}

\section{Introduction}

Theory and observations of seismic anisotropy suggest that the accumulation of stress before earthquakes can be monitored by measuring changes in the time delays between split shear waves along a particular range of ray-path directions in the shear-wave window (Crampin and Zatsepin, 1997; Volti and Crampin, 2003a, b; Gao and Crampin, 2004). Variations in shear-wave splitting are caused by stress-induced variations in microcrack geometry (Crampin and Peacock, 2008). The study is an example of characteristic temporal variations in shear-wave time-delays observed in retrospect before earthquakes. The term stress-forecasting is used rather than prediction to emphasize the different formalism. Also, we well know that at the present time, present methods are not sufficient to precisely determine time and location of earthquakes. However, the methods of probabilistic earthquake forecasting are improving in reliability and skill, and they can provide time-dependent hazard information potentially useful in reducing earthquake losses and enhancing community preparedness and resilience (Jordan et al., 2011). Particularly the fluid-rock deformation based on stress accumulation before large earthquakes can be monitored by analyzing shearwave splitting throughout large volumes surrounding the impending earthquake source zone (Crampin, 2011a). Crampin et al. (1999) clearly indicated that when changes were recognized early enough, the time, magnitude, and fault break of an $M=5$ earthquake in southwest Iceland were successfully stress-forecasted in a narrow time-magnitude window.

To explain the relationship between variations in splitting parameters and low-level (pre-fracturing) deformation, the anisotropic poro-elasticity (APE) model was suggested by Zatsepin and Crampin (1997). This model is based on rock mass deformation with the fundamental assumption that the cracks in the crust are so closely spaced. Moreover, Crampin et al. (2004) indicated that the APE mechanism depends on fluid movement due to flow or diffusion along pressure gradients between neighboring fluid-saturated grain-boundary cracks and low aspect-ratio pores and pore throats at different 


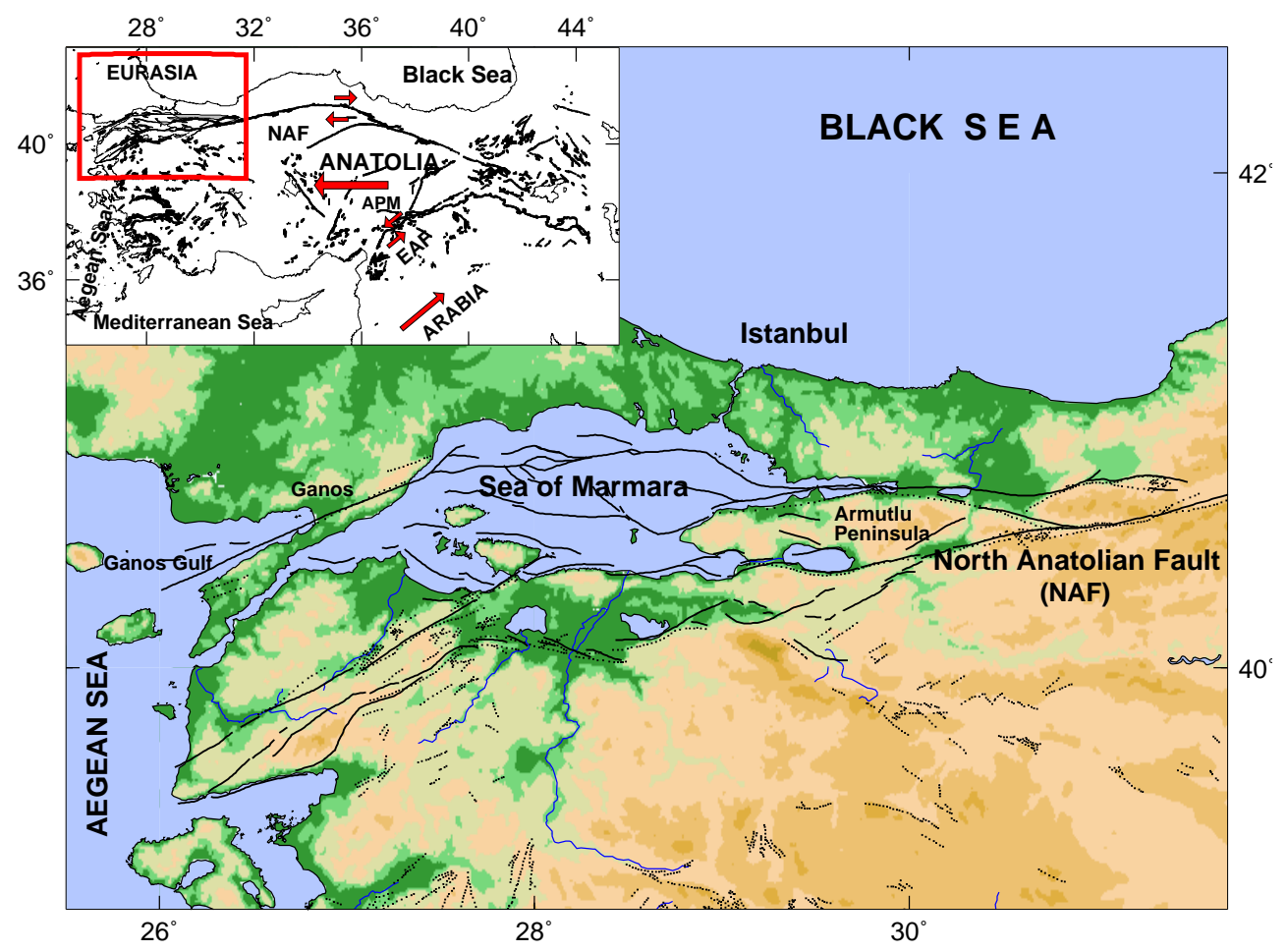

Fig. 1. Tectonic map of Marmara region (dot black faults from Saroglu et al., 1987, thick black faults from Armijo et al., 1999). Inset: The location of the study area within Turkey is marked red.

orientations to the stress-field. Angerer et al. (2002) also show that this model has been accurately calibrated in two controlled-source experiments. For this study, we obviously observe that variations in splitting results before the impending earthquake can be easily explained with the APE model, in particular at GEMT station, because they show a sudden decrease in time delays before the impending earthquake.

Crampin and Peacock (2008) suggest that shear-wave splitting is much misunderstood and identify 17 common fallacies in interpretation that impair many recent analyses of shear- wave. However, using swarms of small earthquakes as the source of shear-waves, 14 characteristic changes in timedelays have been observed, retrospectively, before earthquakes worldwide, with one successful stress-forecast in real time (reviewed by Crampin and Peacock, 2008). In particular, to increase the credibility of the splitting measurements, we considered the fallacies carefully.

This study is a good example of stress-forecast before earthquakes because we obviously observed the characteristic changes in shear-wave splitting that stress-forecast retrospectively the time and magnitude of the $2006, M_{\mathrm{b}}=5.3$ Manyas Earthquake.

\section{Tectonic setting of the study}

Throughout history, the western extension of the North Anatolian Fault Zone (NAFZ) crossing in the Marmara Sea region has been the site of many large and destructive earthquakes (Ambraseys and Zatopek, 1969; Karabulut et al., 2003). Seismological investigations in Western Anatolia, NW Turkey, have identified linear patterns of earthquake epicenters outlining a wedge-shaped block in the area of the Marmara Sea (Demirbag et al., 2007). The Eurasian Plate and the Arabian-African Plate applied a compressional force to the Anatolian Plate (Fig. 1). As a result of these intensive compressional forces against the Anatolian Plate, the North Anatolian Fault Zone (NAFZ) and the East Anatolian Fault Zone (EAFZ) in Northeast-Southwest direction were developed (Fig. 1). Figure 1 also shows the fault systems of Marmara region. The basins in the Marmara Sea are the products of a superimposed evolutionary history defined by two fault systems of different age: the early Miocene-early Pliocene Thrace-Eskisehir Fault Zone, and the late PlioceneRecent North Anatolian Fault and its numerous branches. The area around Istanbul is defined by a well-developed; un-metamorphosed and little deformed continuous Paleozoic sedimentary succession extending from Ordovician to Carboniferous, overlain with a major unconformity, by latest Permian to lowermost Triassic Continental Red Beds (Hoşgören, 1997). In addition, the Sakarya Zone extends 


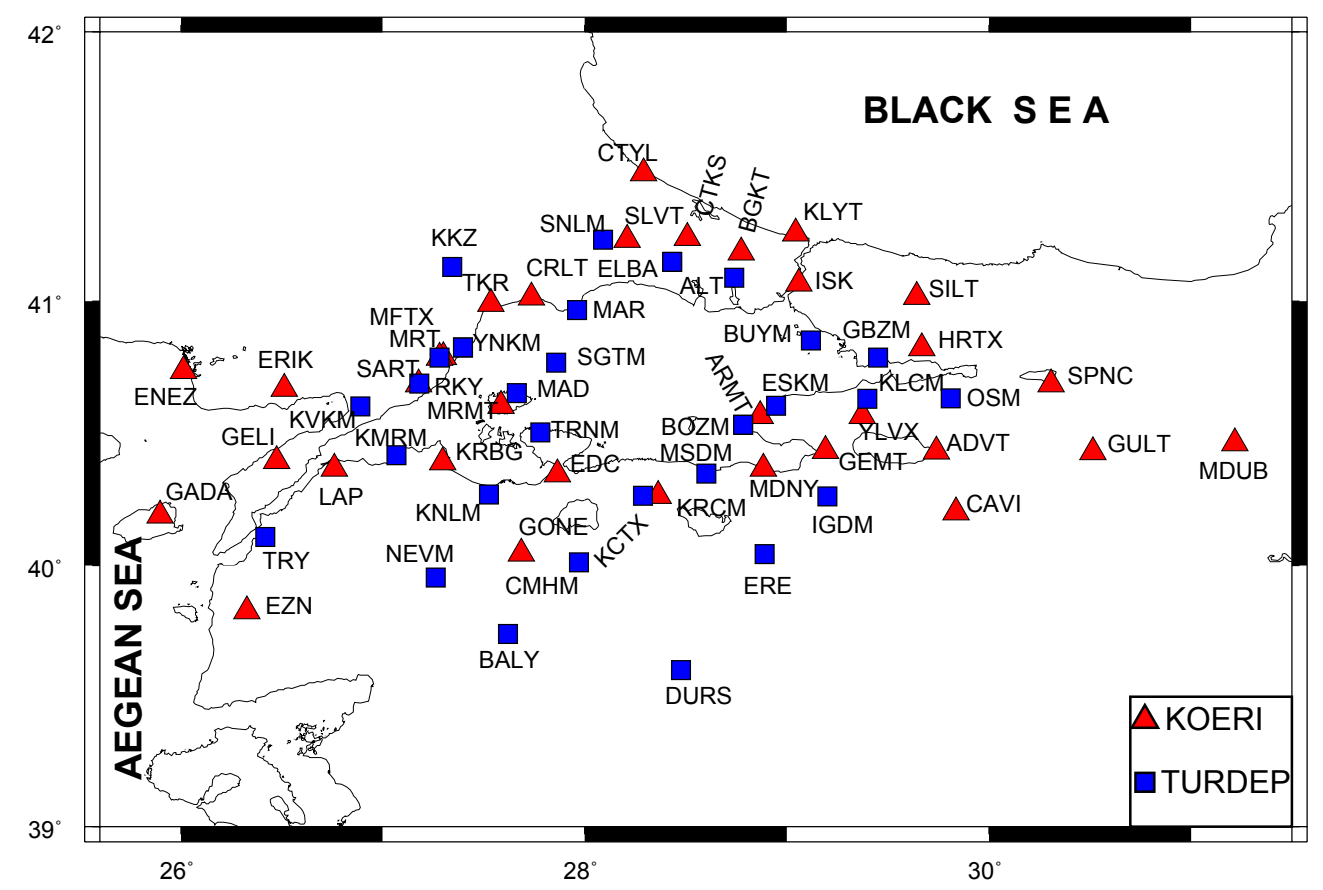

Fig. 2. Seismic stations used in the study. KOERI and TURDEP stations are depicted by red triangles and blue squares respectively.

from the Biga Peninsula in the west to the lesser Caucasus in the east. It is characterized by a variably metamorphosed and strongly deformed. Also, it does not have a Paleozoic basement. Triassic basement, called the Karakaya complex, is overlain with a major unconformity by Liassic conglomerates and sandstones, which progresses to middle Jurassic lower cretaceous limestones and upper cretaceous flysch (Hoşgören, 1997).

The eastern extension of the Marmara Sea, the Izmit Gulf, is an east-west trending active graben, which is dynamically affected by the interaction of the NAFZ and the Marmara Graben systems (Seymen, 1995), is bounded by two horsts: The Kocaeli Peninsula to the north; and the Armutlu Peninsula to the south, showing completely different geomorphological features and a well-defined fault scarp (Ketin, 1967; Okay, 1986). The Armutlu Peninsula and the surrounding regions within the Northwest Anatolia comprise three geologically different zones: southern central and northern. The southern zone corresponds to the Sakarya continent. It essentially consists of thick Mesozoic sedimentary successions (Y1lmaz et al., 1995). The centre zone mainly consists of the Iznik metamorphic assemblage and Geyve metaophiolite. The northern zone is known as the Armutlu metamorphic assemblage and consists of slightly-metamorphosed rocks, interpreted as the Rhodope-Pontide basement (Y1lmaz et al., 1995).

Considering devastating earthquakes, the historical and recent seismicity of the Marmara Region is high, and has critical importance for the earthquake hazard in the Marmara Re- gion, because approximately a fourth of Turkey's population and most industrial centres are within this region. Therefore, it is important to get robust information about temporal variations in stress before impending earthquakes, which we can obtain by studying shear-wave splitting.

\section{Data and methods}

In this study, we used only micro earthquakes recorded by two overlapping networks in the Marmara region (Fig. 2): 29 stations installed by the TURDEP (Multi-Disciplinary Earthquake Research in High Risk Regions of Turkey) Project is conducted by Earth and Marine Sciences Institute, Marmara Research Center, Scientific and Technological Research Council of the Turkish Republic (TÜBITAK) and 33 stations from KOERI (Boğazici University, Kandilli Observatory and Earthquake Research Institute).

Variations in splitting parameters before and after the main shock, Manyas Earthquake, are investigated by three component digital seismograms of micro earthquakes that occurred from January-2006 to December-2006 (Fig. 3). A total of 1216 micro earthquakes are relocated in study area between $39-42 \mathrm{~N}$ and $25.7-31.5 \mathrm{E}$ geographical coordinates by using zSacWin (zSacWin developed by Yilmazer (2003) as an earthquake processing software for KOERI), which is based on HYPO71 (Lee and Lahr, 1975) (Fig. 3). We combined TURDEP data with KOERI after September-2006, since TURDEP project started installing seismic station as of 


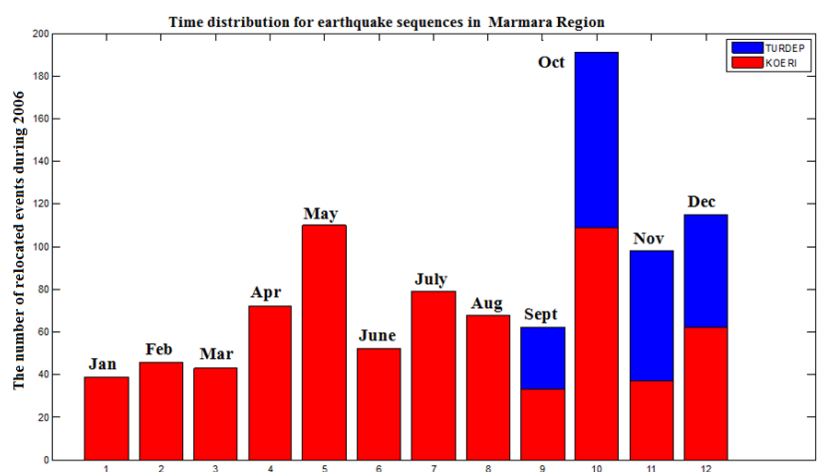

Fig. 3. The relocated events from the KOERI and the TUBITAK stations are marked red and blue from January to December, 2006 respectively. Here we merged only the TURDEP data with the KOERI data for the last 4 months because since the TURDEP stations have been started from September 2006.

September 2006; we used data only from KOERI for the time period of January-September 2006. Arrival times of both $\mathrm{P}$ and $\mathrm{S}$ phases were obtained by visual inspection. Those phases were manually picked with a clear S-wave arrival, which was not always apparent due to high attenuation in region (Horasan, et al., 1998; Bindi et al., 2006). Relocations and the magnitudes are calculated according to $P$ and $S$-waves readings. The duration dependent formula is useful for small and local earthquakes (Bariş et al., 2005). $V_{\mathrm{p}} / V_{\mathrm{s}}=1.73$ value is chosen for routine locations of local seismic events.

Although 1216 micro earthquakes are relocated, more than 175 events are discarded from the data set due to poor quality data. Consequently we have used the data for the shear wave splitting analysis in this study. Then we constrained the data set by the criteria: (1) the standard error of epicenter and depth is less than or equal to $2 \mathrm{~km}$, (2) the number of phase readings is more than 10 , and (3) the rms-value is less than $0.9 \mathrm{~s}$. During analysis of the data, these criteria are certainly considered. After relocation of the events, we checked the quality of the recorded three-component waveforms and rejected those with bad channels in order to acquire the good signal to noise ratio of the incoming wave and identify clearly the impulsive character of the $S$-wave on the seismogram distance between the recorder and the source should be less than $45 \mathrm{~km}$ (Fig. 3). The shear-wave splitting analysis is conducted on waveforms generated by earthquakes that are within the shear-wave window. To avoid contamination from $S$-to- $P$-phase conversions near the surface, the incident angle of a ray path must be less than the critical angle $i c=\sin -1\left(V_{\mathrm{s}} / V_{\mathrm{p}}\right)$ with $V_{\mathrm{p}}$ and $V_{\mathrm{s}}$ being the near-surface velocities of $P$ - and $S$-waves, respectively (Nuttli, 1961; Booth and Crampin, 1985). For a homogeneous half-space with a Poisson's ratio of 0.25 , the critical angle is $i c \sim 35^{\circ}$ (Nuttli, 1961). Because the low-velocity, near-surface layer significantly bends ray paths toward the vertical, a straight- line incident angle of $45^{\circ}$ is adopted as the critical angle in this study (e.g. Shih and Meyer, 1990; Cochran et al., 2003).

Before the analysis of shear wave splitting, the seismograms are low-pass filtered from 2-to- $16 \mathrm{~Hz}$ using a two-way 4-pole Butterworth filter due to enhance local earthquakes. The high-frequency noise is suppressed and the start and end of shear-wave splitting can be determined correctly for each seismogram. Figure 4 shows a three-component seismogram recorded at KMR together with horizontal seismograms rotated into radial and transverse directions. The magnitude 2.8 earthquake was at an epicentral distance of $5.38 \mathrm{~km}$, azimuth 341 , and depth $2.8 \mathrm{~km}$. The seismogram is filtered with a low pass-band of $2-16 \mathrm{~Hz}$. Two horizontal seismograms are rotated into fast and slow directions where the fast and slow shear-waves arrivals, showing clear shear-wave splitting, are marked by vertical lines (Fig. 4a). Figure 4b indicates the screen image of a polarisation diagram display. Reliable seismograms are visually selected for further analysis and the impulsive character of the $\mathrm{S}$ wave is windowed correctly in terms of an ideal time window. Reliable window need to begin before the fast shear-wave arrives and ends after the arrival of the slow direct shear-wave, but before the scattered coda-waves appear. Consequence, each seismogram is reliably windowed to determine splitting parameters: the delay time $\delta t$ between the fast and slow direct shear waves and fast polarization direction after those steps mentioned above are applied to the data.

Crampin (1999) shows that increases of stress increases the average time-delay in Band-1 directions of the shearwave window at the free-surface, where Band-1 are incident rays making $15^{\circ}$-to- $45^{\circ}$ to the plane of the parallel microcracks. The incident shear waves in remainder of the window, Band- 2 directions $0^{\circ}$-to- $15^{\circ}$ to the crack plane, are sensitive to crack density and this is not observed to vary before earthquakes (Crampin and Peacock, 2008). Characteristic patterns of increases in shear-wave time-delays in Band-1 directions (Crampin, 1999), indicating stress-accumulation before impending earthquakes, were first observed in California (Peacock et al., 1988), and later elsewhere (reviewed by Crampin and Peacock, 2008) including observations on Hainan Island, China (Gao et al., 1998). For an understanding of the characteristic patterns of shear-wave behavior before the earthquakes, only persistent earthquake swarms are selected (Fig. 5); because of the characteristic change in shear-wave time-delays, the stress-relaxation decrease is observed whenever there is sufficient swarm activity to monitor time delays. The decrease is interpreted as stress relaxation as micro cracks begin to coalesce onto the fault-plane of the impending earthquake (Crampin and Gao, 2010b). According to these criteria, events are selected for each station (Fig. 6). Approximately more than half of the earthquake data set is not used because earthquakes are not compatible with the criteria mentioned above. A variety of methods have been developed for measuring time-delays and polarizations of shear-wave splitting. Although there are a number of 


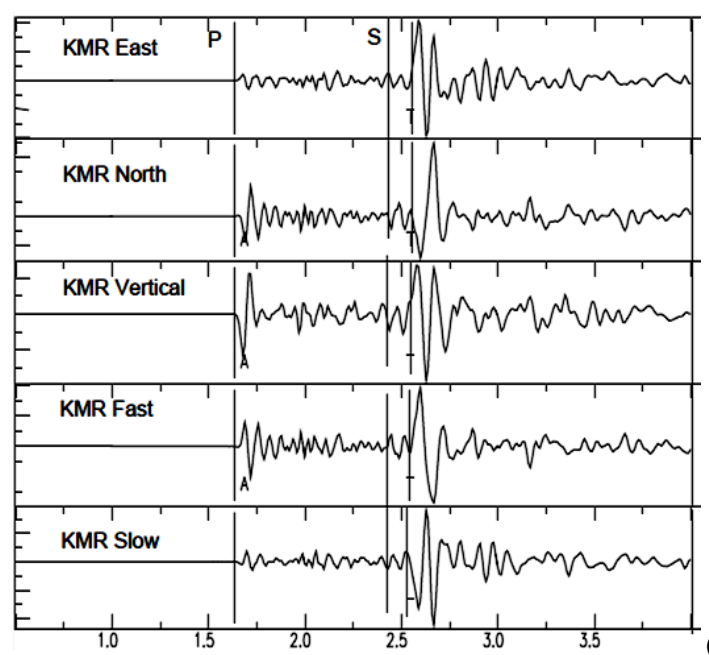

(a)
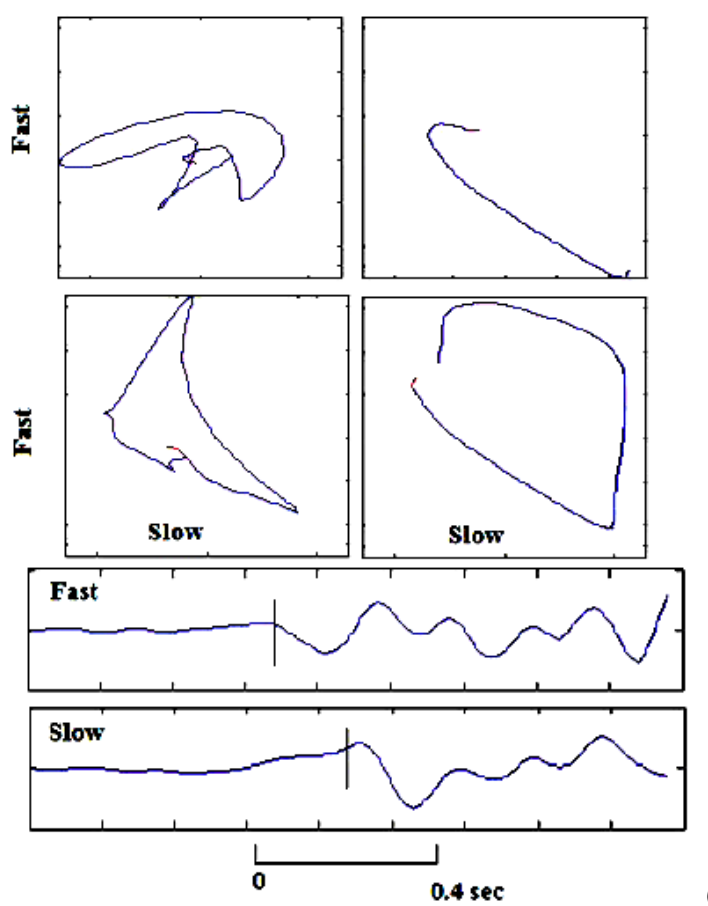

(b)

Fig. 4. (a) Screen image from shear wave splitting analysis before Splitting processing. Three-component seismogram at a rate of 100 samples per second of a magnitude 2.8 earthquake recorded at Station KMR of TURDEP seismic network in Marmara. Time axis is in seconds. From top to bottom, seismograms are EW-, NS, vertical-, and rotated horizontal components respectively. P- and S-wave arrivals from the study seismic catalogue are also marked on the original seismograms. (b) Screen image of polarisation diagrams for possible adjustment of polarisation and time-delay is shown. Fast and slow shear-wave picks are shown in horizontal polarisation diagrams in time interval $1 \mathrm{~S}$ and $2 \mathrm{~S}$. First and last points of time-delay and directions are determined by visual adjustment.

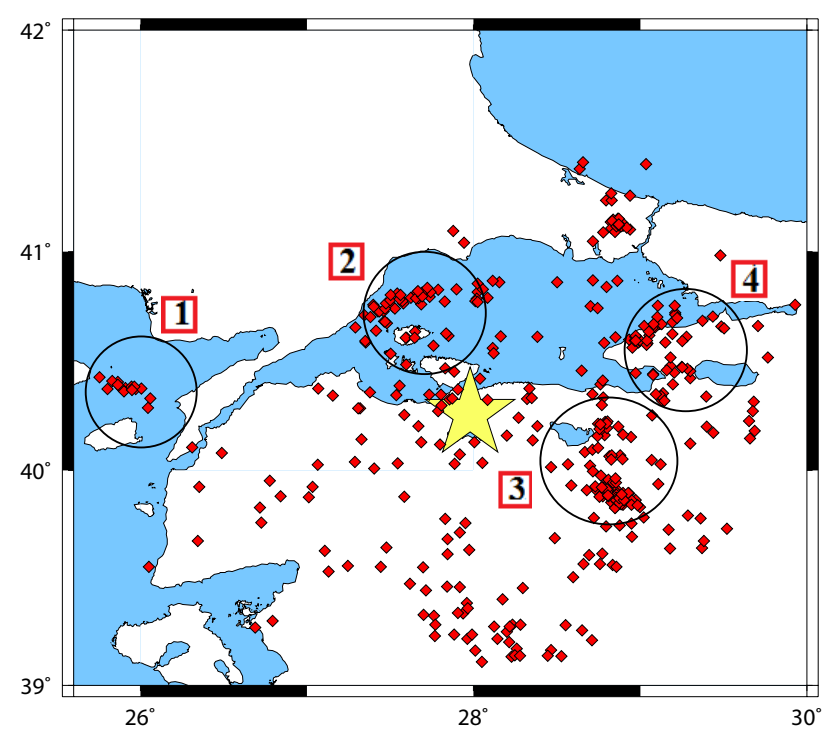

Fig. 5. Distribution of micro earthquakes before the main earthquake (Main earthquake: yellow star, micro-earthquakes: red diamonds). Clusters (in black circle) of earthquakes used in analysis from west to east: (1) Gulf of Saroz; (2) Tekirdağ-Murefte; (3) SW Bursa; and (4) Cinarcik-Yalova (see also Fig. 1).

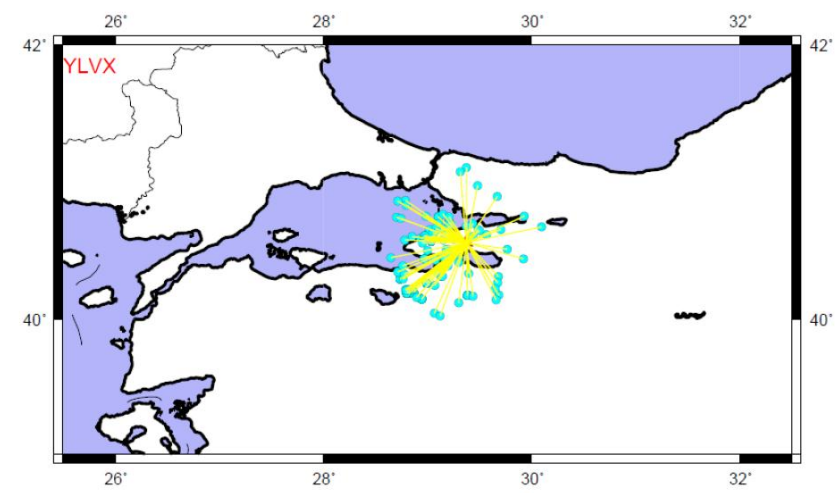

Fig. 6. The events are used to determine splitting parameters at YLVX station. All earthquake distances are less than $45 \mathrm{~km}$.

automatic or almost fully automatic techniques have been developed, automatic techniques are not reliable for measuring shear-wave in crustal earthquakes because of severe disadvantages (Crampin and Gao, 2006). Although visual techniques are more accurate than automatic or almost fully automatic techniques, visual techniques may be not objective and are time consuming. Crampin and Peacock (2008) discuss common fallacies in interpretation concerning seismicshear wave splitting of the crustal structure of the Earth and here will not repeated.

In particular, the major difficulty in measuring shear-wave splitting above small earthquakes is that shear-waves have complicated signatures into three-component seismograms 
where polarizations, and particularly time-delays, are heavily scattered and vary widely in time and space (Crampin and Gao, 2006). In this study we measure splitting parameters by using the techniques of aspect ratio, cross-correlation, and systematic analysis of crustal anisotropy (Peng and BenZion, 2004) in order to obtain reliable accurate splitting parameters. We observed that the aspect ratio and crosscorrelation are more reliable than the automatic systematic analysis of crustal anisotropy (Peng and Ben-Zion, 2004) when we compared results from manual methods with the automatic method. Finally, we can say that such results from the automatic method are responsible for making unreliable interpretations on orientation and strength of anisotropy (Crampin and Peacock, 2008).

\section{Results}

Strong earthquake clusters in Marmara Region (Fig. 5) before the 2006 Manyas EQ are located in active fault systems in the region (Fig. 1). We examined and relocated earthquake clustering in space and time before and after the 2006 Manyas earthquake in order to monitor the build-up of stress before earthquakes and the stress release as earthquakes occur. The distribution of seismic activity in the study area is not uniform in the period January-December 2006. We thus examined distribution of micro events in longitude and latitude specified in terms of julday (day number of a year) and in terms of depth to understand the main character of seismic stress in the region (Fig. 7a, b). We also examined the relationship between magnitude and time (julday) because we expected variations in magnitude would be related to time and stress accumulation relative to the fault system (Fig. 7c). However, we observed that magnitudes of nearly all events are slightly less than 3 during $1 \mathrm{yr}$ (Fig. 7c). It means that magnitude of the earthquakes could not be remarkably changed before and after the 2006 Manyas EQ.

Most of the micro earthquakes occurred at shallow depths from May 2006 to August 2006 between $27.8^{\circ}-29.3^{\circ}$ longitude and $40^{\circ}-40.7^{\circ}$ latitude. Continuous well-distributed seismic activity was observed during one year-2006 (Fig. 7a, $\mathrm{b}, \mathrm{c})$. Here the goodness of fit 1 with the data is evaluated with linear polynomial at Fig. 7c. Fitting a data set consisting of the magnitude and the juldays of the used earthquakes with a fit 1 model is a good visual way to examine of the fitted curve. The bound is defined with the level of certainty of $95 \%$.

A smooth change between magnitude and julday are observed in Fig. 7c. The relation between magnitude and julday is not proportional. It might be related to the complex redistribution of stresses and dynamic strains imposed by the dislocation of the main shock.

In the study, some stations are selected regarding the distances to the main shock in order to observe changes in stress before the main earthquake and compare them with each other (Fig. 8a, b, c). The particular stations were selected regarding of distance from earthquake clusters (Fig. 5). The rest of the stations were far away from the clusters, so that they are not selected for the splitting analysis since the large distance between an event and a receiver may enlarge the amplitudes of the S phase, making it hard to determine the beginning and the ending time of the $\mathrm{S}$ phase on the waveform. Therefore, we avoided the distorted $\mathrm{S}$ wave due to the high attenuation. The earthquake swarm was paraticularly strong during May-2006 (Fig. 3). Time-delays in Band 1 at YLVX station suddenly decreased nearly on May-2006 (Fig. 8a). However, in the meantime, there is remarkable increase in time-delays in Band-2 at YLVX station between mid-July and mid-August, 2006 (Fig. 8a). In accordance with measurements from 1 January 2006 to 20 October 2006, scatter in time-delays is clearly observed at YLVX (Fig. 8a).

Further, depth range from 0 to $25 \mathrm{~km}$, the number of earthquakes, also gradually increased from January 2006 to 20 October 2006 (Fig. 7b). This might be related to stress accumulations before the 2006 Manyas-Kus Golu earthquake. The average focal depth also gradually increased during the period. From 20 July 2006 to 10 October 2006, the scatter in time-delays is clearly observed at GEMT despite the few splitting measurements. Depth range is not stable because of continuous changes in depth parameter of micro events during the period at the surrounding area of the GEMT Station. The anisotropic pattern in lag times at YLVX Station is similar to GEMT Station from 20 July 2006 to 10 October 2006 (Fig. 8a, b). However, location of both two stations is roughly the same, but weighted average polarization direction at GEMT station is not similar to YLVX station (Fig. 9). MRMX station is closer to the 2006 Manyas EQ than the YLVX and GEMT stations.

We observed that delay times are very scattering until midJuly 2006 (Fig. 8c). The scattering pattern is observed in the Band- 1 and the Band-2. After mid-July 2006, delay times abruptly decrease. But it is difficult to interpret the observation because our measurements are very limited from May 2006 to mid-July 2006. Considering all measurements from January 2006 to 20 October 2006, the scatter in time delays is clearly seen at MRMX Station. In this study, weighted average splitting parameters are also calculated for each station that used in the study. However, for some stations, weighted average splitting parameters are ambiguous such as ENEZ. It means that delay times are $0.3 \mathrm{~s}$ larger than we expected. For such stations, weighted average polarization directions are hence not shown on the splitting map (Fig. 9). Although distribution of weighted average for per station from micro events is not uniform, most of weighted average fast polarization directions in the western part of the study are approximately NE-SW except at RKY Station. Further, weighted average fast polarization directions in eastern Marmara are very scattering (Fig. 9). Although some stations are located in a small area, their weighted polarization directions are nearly perpendicular to each other (Fig. 9). After the main 

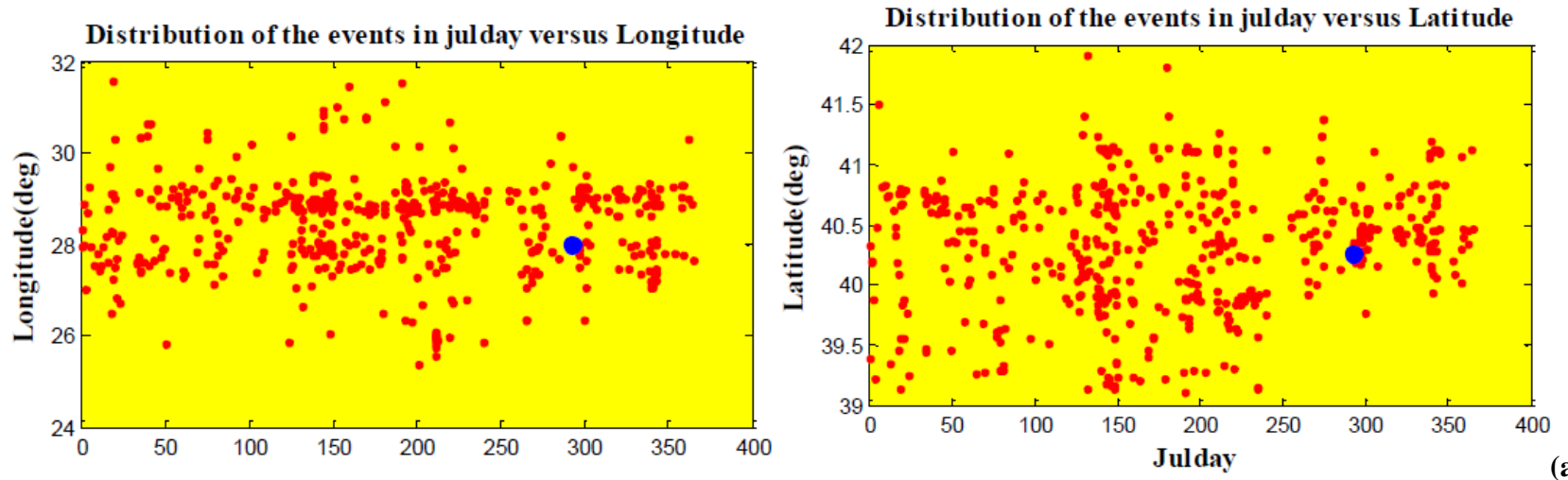

(a)
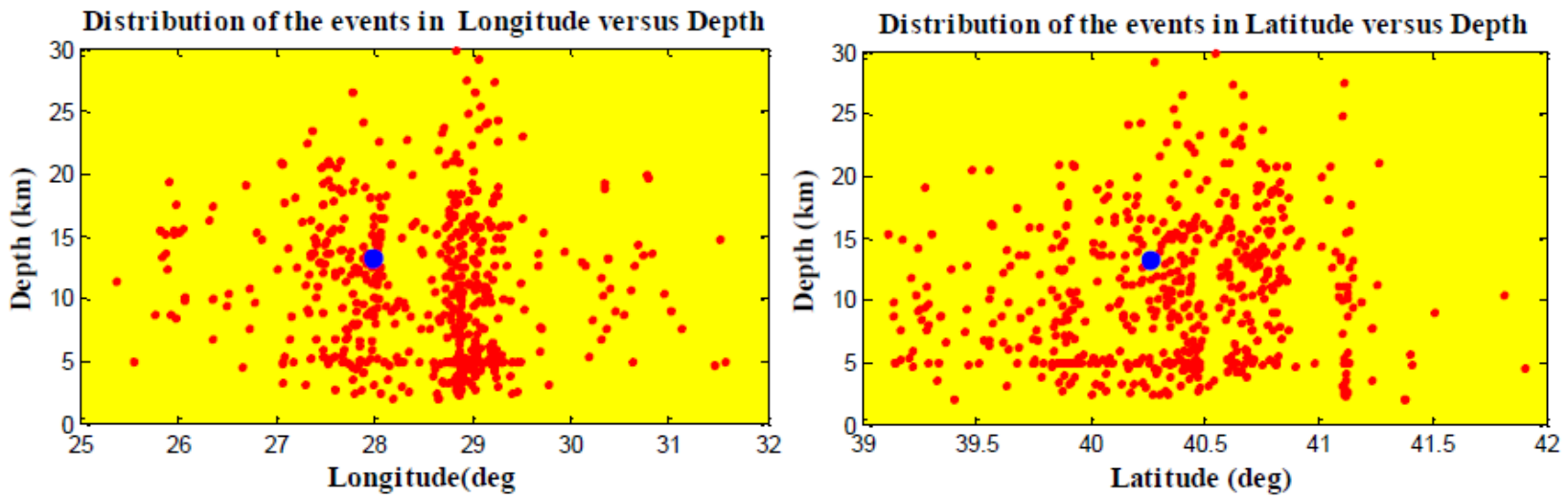

(b)

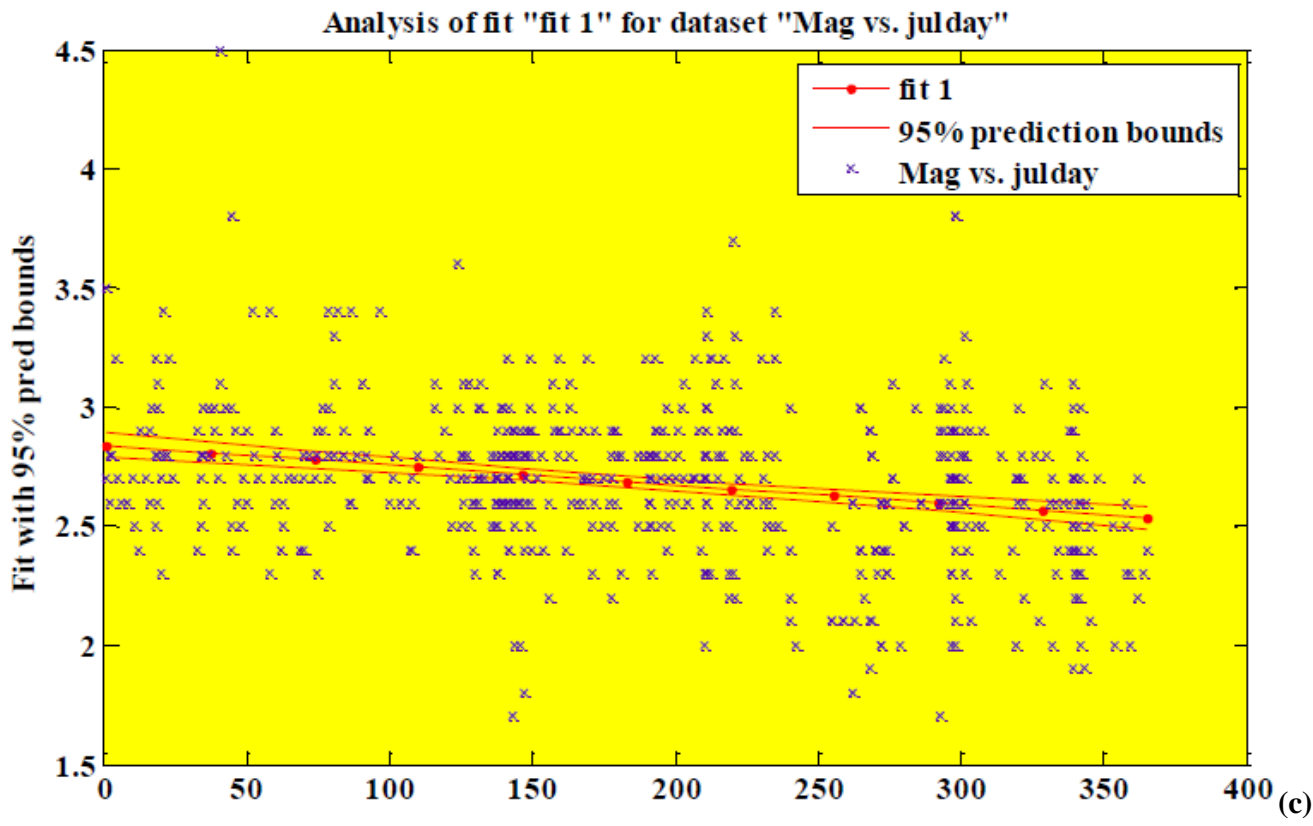

Fig. 7. (a) Distribution of micro events in longitude and latitude versus julday. Micro earthquakes are depicted by red dots. The main event is marked blue. (b) Distribution of micro events in longitude and latitude versus depth. Micro earthquakes and the main even are depicted by red dots and blue circle respectively (c) Analysis of the relationship between magnitude and julday. 

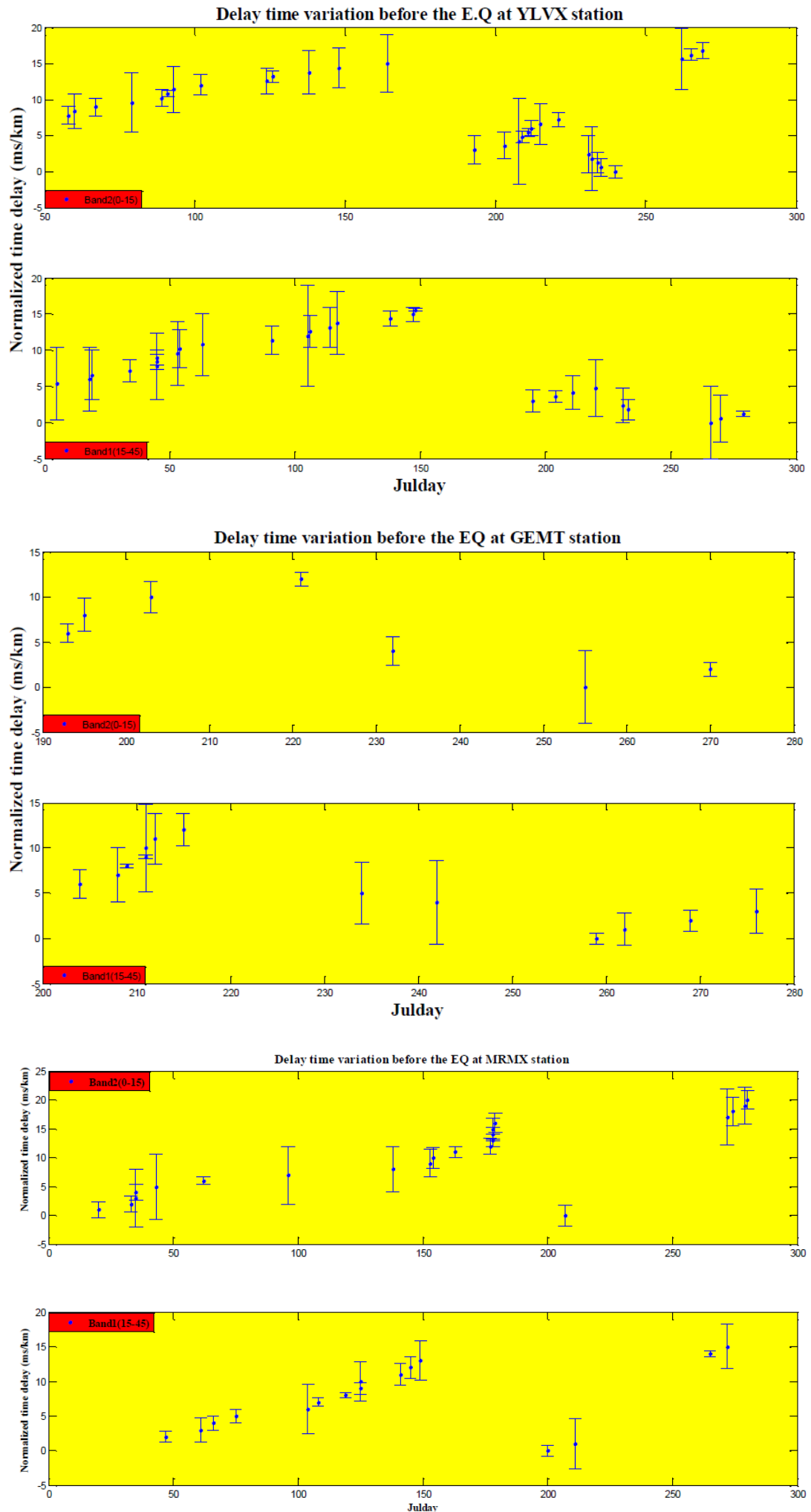

Fig. 8. (a) Variations of time-delays between split shear waves for 1 January 2006 to 19 October 2006 at station YLVX. (b) Variations of time-delays between split shear waves for 1 January 2006 to 19 October 2006 at station GEMT. (c) Variations of time-delays between split shear waves for 1 January 2006 to 19 October 2006 at station MRMX. 
earthquake, the number of micro events gradually decreased. However, some stations such as GEMT still show remarkable variations in delay times (Fig. 10). Estimated delay times are remarkably increased in Band-2 (Fig. 10). This may be related to the location of the station that is located in one of the branches of the NAFZ (Fig. 1).

\section{Discussion and conclusion}

In this study, a $M_{\mathrm{b}}=5.3$ Manyas EQ has been retrospectively "stress-forecasted" by using variations in time delays to evaluate the time and magnitude at which stress-modified micro cracking reaches fracture criticality within the stressed volume where strain is released. The times and magnitudes of impending larger earthquakes may be estimated by using such modifications in shear-wave splitting since stressinduced changes to microcrack geometry can be monitored by variations in shear-wave splitting (Crampin and Peacock, 2008).

Our measurements obtained from micro earthquakes clearly display the large $\pm 80 \%$ scatter in time-delays and polarizations that is always observed above small earthquakes (Crampin, 1999) (Fig. 8a, b, c). It means that shear-wave splitting parameters are very sensitive to the variations in stress. In such studies, one of the major problems is the lack of sufficient high-quality data before and after a large earthquake in suitable station-to-earthquake recording geometries. In our study, azimuthal coverage and density of stations are approximately enough and allow us to monitor the variations in splitting parameters. Before the 2006 Manyas EQ, sufficiently persistent swarm activity is also observed (Fig. 3). The swarms are very crucial for stress-forecasting since only such persistent swarms are able to provide reliable shearwave source signals throughout the build-up of stress.

Another vital point for detecting temporary variation in splitting parameters is available measurement techniques. Currently, automatic measurement techniques are wholly successful (Crampin and Gao, 2006). However, all available methods for measuring splitting parameters are not enough. Thus, we preferred using the visual methods as they are more accurate than automatic or almost fully automatic techniques. In particular, we used three methods to minimize the measurements errors depending on free surface and crustal heterogeneity.

Time-delays in seismic shear-wave splitting measurements above small earthquakes typically display a scatter of often as much as \pm 80 per cent about the mean (Crampin et al., 2004a). The large $\pm 80 \%$ scatter in time-delays obtained from micro earthquakes before the main event at some stations such as YLVX Station is observed (Fig. 8a). But the delay time pattern of MRMX is different from others (Fig. 8c). It is probably related to the location of the MRMX station (Fig. 2) because it is intensively subjected to more stress than YLVX and others in accordance to high seismic activity before the main event. The measured splitting parameters at this station become very sensitive to small changes in stress due to high seismic activity. Also, It is clearly observed that a $M=5$ earthquake is able to lead to changes in splitting measurements that are obtained from a distance of $1000 \mathrm{~km}$ (Crampin and Gao, 2010a), since the critical systems of stress-aligned fluid-saturated microcracks have influence on the sensitivity at distances of hundreds of times the conventional source dimensions.

There are many earthquakes that occurred and their magnitudes were greater than 3 . It means that accumulation of stress has a big impact on the area of seismic activity before the impending event. Thus, just one event is sufficient to monitor the changes in estimated parameters. Accumulation of stress surrounding the main event has a significant influence on variations in delay times of Band-2. The finding is observed at MRMX Station. Before approximate 3 months from the 2006 Manyas EQ, fluctuations in cumulative delay times are also remarkable, as observed in Band-2 (015) of YLVX Station (Fig. 8a). It might be related to large changes in stress resulting in an increase crack density beneath the station. Active fault systems and fluid in crack systems also have influence on variation in determined splitting parameters. The large $\pm 80 \%$ scatter and the theoretical variation of time-delays in Band-1 frequently hide correlations of time-delays with distance or depth, except for very substantial data sets, when averages are meaningful (Crampin et al., 2004a). The scattering in time delays is related to stressinduced changes in crack geometry (Fig. 8a). In particular, variations in Band-1 for YLVX, MRMX and GEMT are related to low-level stress and are only likely to affect crack aspect ratios which will change the average time-delay in Band-1 (Fig. 8a, b, c).

The large $\pm 80 \%$ scatter in time-delays and polarisations at the stations such as YLVX is related to high pore-fluid pressures on all seismically active fault-planes (Crampin et al., 2004a). The observed anisotropy might result from the upper half or whole upper part of the crust. Rapid changes in delay times and weighted average fast polarization directions between neighboring seismic stations such as YLVX and GEMT might be related to the localization of anisotropy and means that it should be confined to the near-surface (Crampin and Peacock, 2008). It is difficult to evaluate the depthrange because observed shear-wave time-delays are the cumulative sum of the time-delays along the whole of the ray path. So, we expect that such stress-aligned anisotropy is uniformly distributed below such depths throughout at least the upper half of the crust but clear, direct evidence of shallow anisotropy is not available.

Although the weighted average fast polarization at most stations show approximately a similar patter, the distribution of fast polarization direction is not uniform in the Eastern Marmara and the Western Marmara (Fig. 9). The variations in the weighted average fast polarization directions are 


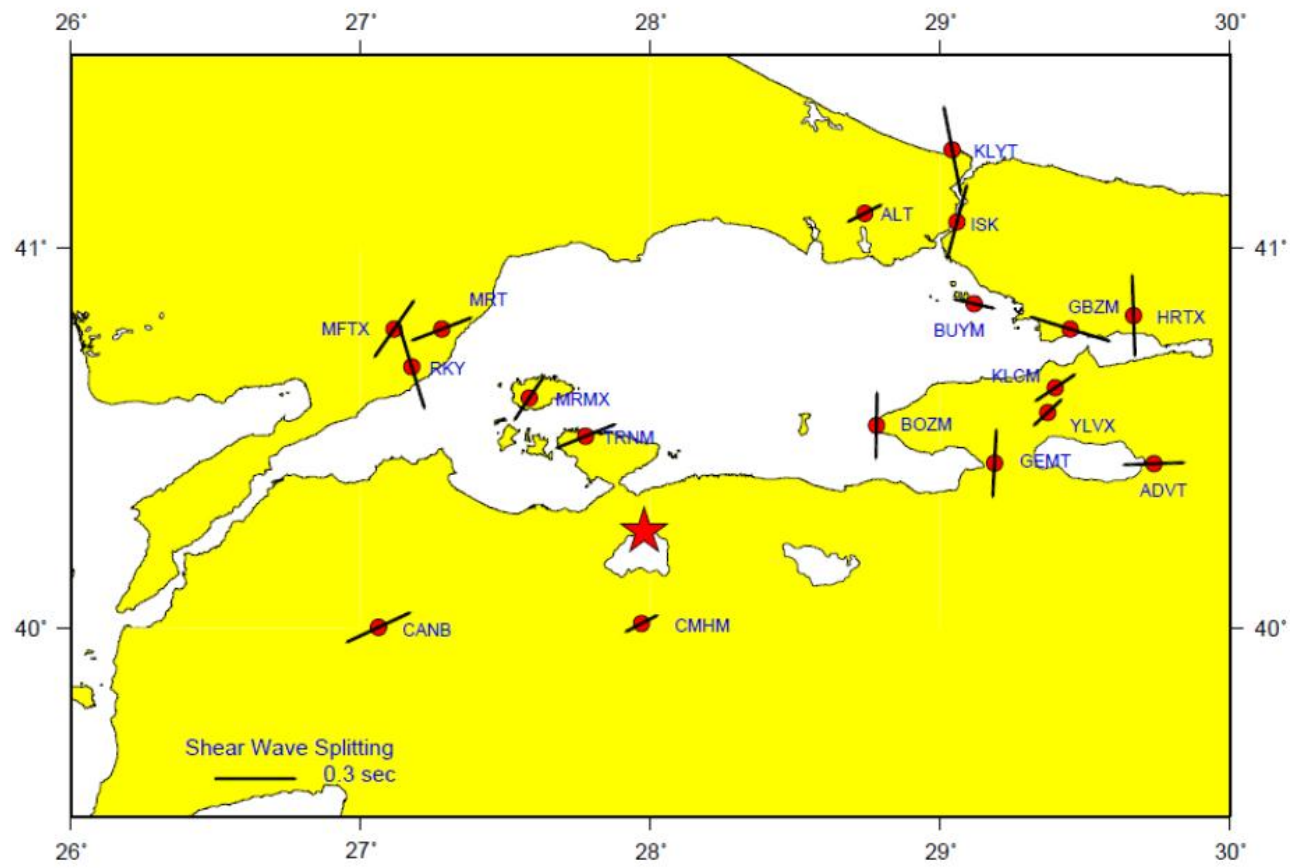

Fig. 9. Distribution of weighted Average results for per station before the main earthquake Main earthquake is marked red.

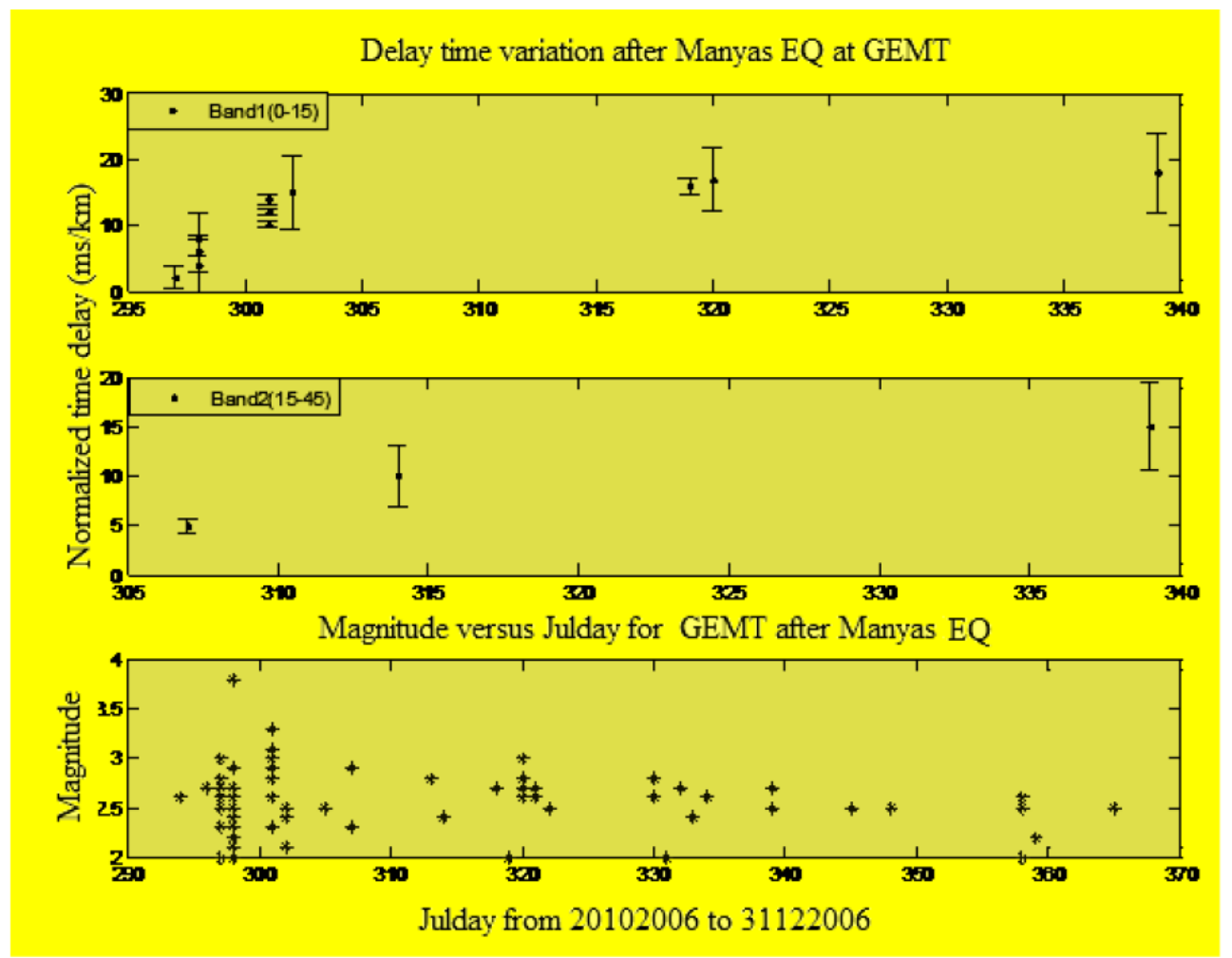

Fig. 10. Changes in delay time after the main earthquake at station GEMT. Micro earthquakes after the main earthquake occurred. They are marked asterix. 
probably related to the tectonic structure of the Marmara region. In particular, the region of the Marmara Sea is a transition zone between the strike slip regime of the NAFZ and the extension regime of the Aegean Sea (Taymaz, et al., 2004).

After the main earthquake, we observed an obvious increase in delay time at GEMT Station and seismic activity at the surrounding area that were very strong (Fig. 10). Increases in time delays of shear wave splitting monitoring stress accumulation before earthquakes are also not precursory to earthquakes.

Finally, considering variations in splitting parameters before and after the main earthquake, it is very hard to conclude that the location of the forecast earthquake can be forecasted (Jordan et al., 2011). But we believe that such a study provides an understanding of how a change in crack density and crack ratio with the accumulation of stress could be recognized at substantial distances from the impending earthquake epicentre.

Acknowledgements. This work has been supported by TURDEP project (105G019) which is funded by tubitak taral 1007 program. We would like to thank the staffs of KOERI and TUBITAK-MAM for providing data.

Edited by: M. E. Contadakis

Reviewed by: two anonymous referees

\section{References}

Ambraseys, N. N. and Zatopek, A.: The Mudurnu Valley earthquake of July 22nd 1967, Bull. Seism. Soc. Am., 59, 521-589, 1969.

Angerer, E., Crampin, S., Li, X.-Y. and Davis, T.L.: Processing, modelling, and predicting time-lapse effects of over-pressured fluid-injection in a fractured reservoir, Geophys. J. Int., 149, 267-280, 2002.

Armijo, R., Meyer, B., Hubert, A. and Barka, A.A.: Westward Propagation of the North Anatolian Fault into the Northern Aegean: Timing and Kinematics, Geology, 27, 267-270, 1999.

Bariş, S., Nakajima, J., Hasegawa, A., Honkura, Y., Ito, A., and Ucer, S. B.: Three-dimensional structure of $\mathrm{Vp}, \mathrm{Vs}$ and $\mathrm{Vp} / \mathrm{Vs}$ in the upper crust of the Marmara region, NW Turkey, Earth Planets Space, 57, 1019-1038, 2005.

Bindi, D., Parolai, S., Grosser, H., Milkereit, C., and Karakisa, S.: Crustal Attenuation Characteristics in Northwestern Turkey in the Range from 1 to $10 \mathrm{~Hz}$, Bull. Seismol. Soc. Am., February 2006, 96, 1, 200-214, 2006.

Booth, D. C., Crampin, S., Evans, R., and Roberts, G.: Shearwave polarizations near the North Anatolian Fault - Evidence for anisotropy-induced shear-wave splitting, Geophys. J. R. Astron. Soc., 83, 61-73, 1985.

Crampin, S.: Calculable fluid-rock interactions, J. Geol. Soc., 156, 501-514, 1999

Crampin, S.: A Second Opinion on "Operational earthquake forecasting: Some thoughts on how and why," by Thomas Jordan and Lucille Jones, Seism. Res. Lett., 82, 227-230, 2011 a.
Crampin, S. and Gao, Y.: A review of techniques for measuring shear-wave splitting above small earthquakes, Phys. Earth. Planet. Inter., 159, 1-14, 2006.

Crampin, S. and Gao, Y.: Earthquakes can be stress-forecast, Geophys. J. Int., 180, 1124-1127, 2010a.

Crampin, S. and Gao, Y.: A review of a new understanding of fluidrock deformation in the crack-critical crust, in Rock Stress and Earthquakes, CRC Press, Taylor \& Francis Group, London, 235240, 2010b.

Crampin, S. and Peacock, S.: A Review of the current understanding of shear-wave splitting in the crust and common fallacies in interpretation, Wave Motion, 45, 675-722, 2008.

Crampin, S. and Zatsepin, S. V.: Changes of strain before earthquakes: the possibility of routine monitoring of both long-term and short-term precursors, J. Phys. Earth, 45, 1-26, 1997.

Crampin, S., Volti, T. and Stefansson, R.: A successfully stressforecast earthquake, Geophys. J. Int., 138, F1-F5, 1999.

Crampin, S., Peacock, S., Gao, Y., and Chastin, S.: The scatter of time-delays in shear-wave splitting above small earthquakes, Geophys. J. Int., 156, 39-44, 2004a.

Cochran, E. S., Vidale, J. E., and Li, Y. G.: Near-fault anisotropy following the Hector Mine earthquake, J. Geophys. Res., 108, 2436, doi:10.1029/2002JB002352, 2003.

Demirbag, E., Kurt, H., Dusunur, D., Sarıkavak, K., and Cetin, S.: Constructing a 3D structural block diagram of the Central Basin in Marmara Sea by means of bathymetric and seismic data, Mar. Geophys. Res., 28, 343-353, doi:10.1007/s11001-007-9036-3, 2007.

Gao, Y. and Crampin, S.: Observations of stress relaxation before earthquakes, Geophys. J. Int., 157, 578-582, 2004.

Gao, Y., Wang, P., Zheng, S., Wang, M., Chen, Y., Zhou, H.: Temporal changes in shear-wave splitting at an isolated swarm of small earthquakes in 1992 near Dongfang, Hainan Island, southern China, Geophys. J. Int., 135, 102-112, 1998.

Horasan, G., Kaslılar-Ozcan, A., Boztepe-Guney, A., and Turkelli, N.: S-wave attenuation in the Marmara Region, northwestern Turkey, Geophys. Res. Lett., 25, 14, 2733-2736, 1998.

Hoşgören, M. Y.: Jeomorfoloji'nin Ana Cizgileri I, Rebel Yayincilik, Istanbul, 1997 (in Turkish).

Jordan, H., Chen, Y. T., Gasparini, P., Madariaga, R., Main, I., Marzocchi, W., Papadopoulos, G. P., Sobolev, G. A, Yamaoka, K., and Zschau, J.: Operational Earthquake Forecasting: State of Knowledge and Guidelines for Utilization, Ann. Geophys., 54, 4, 316-391, doi:10.4401/ag-5350, 2011.

Karabulut, H., Bouin, M., Bouchon, M., Dietrich, M., Cornu, C. M., and Aktar, M.: The seismicity in the eastern Marmara Sea after 17 August 1999 Izmit Earthquake, Bull. Seism. Soc. Am., 92, 382-393, 2003.

Ketin, I.: Bolu -Gerede - Mengen ve Y $\iota$ g $\iota$ lca bölgesindeki Paleozoyik olusuklara ait jeolojik rapor, TPAO Arama Grubu Rap No:379, unpublished, 1967 (in Turkish).

Lee, W. H. K. and Lahr, J. C.: HYP071 (Revised): A computer program for determining hypocenter, magnitude, and first motion pattern of local earthquakes, U.S. Geol. Surv. Open File Report 75-311, 113 pp., 1975.

Nuttli, O.: The effects of the Earth's surface on the $\mathrm{S}$ wave particle motion, Bull. Seismol. Soc. Am., 51, 237-246, 1961.

Okay, A.I.: Tectonic units and sutures in the pontides, Northern Turkey. Tectonic evolution of the Tethyan Region, NATO ASI 
Series, Series C-Vol., 259, 109-116, 1986.

Peng, Z. and Ben-Zion, Y.: Systematic analysis of crustal anisotropy along the Karadere-Duzce branch of the North Anatolian fault, Geophys. J. Int., 159, 253-274, 2004.

Seymen, I.: Geology of the Izmit Gulf region (NW Turkey), in: edited by: Meriç, E., Quaternary sequence in the Gulf of Izmit, Turkish Navy Press, Istanbul, 1-23, 1995 (in Turkish).

Shih, O. R. and Meyer, P. R.: Observation of Shear Wave Splitting From Natural Events "South Moat of Long Valley Caldera", California, June 29 to August 12, 1982, J. Geophys. Res., 95, 11179-11195, 1990.

Saroglu, F., Boray, A., and Emre, O.: Active faults of Turkey, Dissertation, Mineral Research and Exploration Institute of Turkey, 1987.

Taymaz, T., Tan, O., and Yolsal, S.: Recent Devastating Earthquakes in Turkey and Active Tectonics of the Aegean and Marmara Seas, Earthquake Monitoring and Seismic Hazard Mitigation in Balkan Countries; NATO Science Series: IV: Earth and Environmental Sciences, 81, II, 47-55, doi:10.1007/978-1-40206815-7_3, 2008.
Volti, T. and Crampin, S.: A four-year study of shear-wave splitting in Iceland: 1. Background and preliminary analysis, in New insights into structural interpretation and modelling, edited by: Nieuwland, D. A., Geol. Soc. Lond., 212, 117-133, 2003 a.

Volti, T. and Crampin, S.: A four-year study of shear-wave splitting in Iceland: 2. Temporal changes before earthquakes and volcanic eruptions, in New insights into structural interpretation and modelling, edited by: Nieuwland, D. A., Geol. Soc. Lond., 212, 135-149, 2003b.

Yılmaz, Y., Genç, S. C., Yiğitbaş, E., Bozcu, M., and Yılmaz, K.: Geological evolution of the late Mesozoic continental margin of the North western Anatolia, Tectonophysics, 155-171, 1995.

Y1lmazer, M.: zSacWin (Kandilli earthquake processing software) is developed for KOERI: http://www.koeri.boun.edu.tr/, 2003.

Zatsepin, S. V. and Crampin, S.: Modelling the compliance of crustal rock: I-response of shear-wave splitting to differential stress, Geophys. J. Int., 129, 477-494, 1997. 